\title{
Oral Phenelzine Treatment Mitigates Metabolic Disturbances in Mice Fed a High-Fat Diet
}

\author{
๑ Josep Mercader, Agustín G. Sabater, Sophie Le Gonidec, Pauline Decaunes,

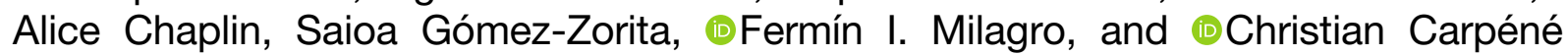 \\ Balearic Islands Health Research Institute, Palma de Mallorca, Spain (J.M.); Department of Fundamental Biology and Health \\ Sciences, University of Balearic Islands (UIB), Palma de Mallorca, Spain (J.M.); Alimentómica, S.L., Spin-off from UIB, Palma de \\ Mallorca, Spain (A.G.S.); Institute of Metabolic and Cardiovascular Diseases, INSERM, UMR1048, Teams 1 \& 3, Toulouse, \\ France (C.C., S.L.G., P.D.); I2MC, University of Toulouse, UMR1048, Paul Sabatier University, Toulouse Cedex 4, France (C.C., \\ S.L.G., P.D.); Cardiovascular Research Institute, School of Medicine, Case Western Reserve University, Cleveland, Ohio (A.C.); \\ Nutrition and Obesity Group, Department of Nutrition and Food Science, University of the Basque Country and Lucio Lascaray \\ Research Institute, Vitoria, Spain (S.G.-Z.); CIBERobn Physiopathology of Obesity and Nutrition, Institute of Health Carlos III, \\ Madrid, Spain (S.G.-Z., F.I.M.); Department of Nutrition, Food Science, and Physiology, University of Navarra, Pamplona, Spain \\ (F.I.M.); and Centre for Nutrition Research, University of Navarra, Pamplona, Spain (F.I.M.)
}

Received May 9, 2019; accepted July 1, 2019

\section{ABSTRACT}

Novel mechanisms and health benefits have been recently suggested for the antidepressant drug phenelzine (PHE), known as a nonselective monoamine oxidase inhibitor. They include an antilipogenic action that could have an impact on excessive fat accumulation and obesity-related metabolic alterations. We evaluated the metabolic effects of an oral PHE treatment on mice fed a high-fat diet (HFD). Eleven-week-old male C57BL/6 mice were fed a HFD and either a $0.028 \%$ PHE solution (HFD + $\mathrm{PHE}$ ) or water to drink for 11 weeks. PHE attenuated the increase in body weight and adiposity without affecting food consumption. Energy efficiency was lower in HFD + PHE mice. Lipid content was reduced in subcutaneous fat pads, liver, and skeletal muscle. In white adipose tissue (WAT), PHE reduced sterol regulatory element-binding protein-1c and phosphoenolpyruvate carboxykinase mRNA levels, inhibited amine-induced lipogenesis, and did not increase lipolysis. Moreover, HFD + PHE mice presented diminished levels of hydrogen peroxide release in subcutaneous WAT and reduced expression of leukocyte transmigration markers and proinflammatory cytokines in visceral WAT and liver. PHE reduced the circulating levels of glycerol, triacylglycerols, high-density lipoprotein cholesterol, and insulin. Insulin resistance was reduced, without affecting glucose levels and glucose tolerance. In contrast, PHE increased rectal temperature and slightly increased energy expenditure. The mitigation of HFD-induced metabolic disturbances points toward a promising role for PHE in obesity treatment and encourages further research on its mechanisms of action.

\section{SIGNIFICANCE STATEMENT}

Phenelzine reduces body fat, markers of oxidative stress, inflammation, and insulin resistance in high-fat diet mice. Semicarbazide-sensitive amine oxidase, monoamine oxidase, phosphoenolpyruvate carboxykinase, and sterol regulatory element-binding protein-1c are involved in the metabolic effects of phenelzine. Phenelzine could be potentially used for the treatment of obesity-related complications.

\section{Introduction}

Phenelzine (PHE; $\beta$-phenylethylhydrazine) is a nonselective monoamine oxidase (MAO) inhibitor prescribed to treat depression and anxiety disorder, which has been superseded by novel drugs, partly due to its side effects, which include hypertensive crisis, hypoglycemia, food cravings, and body weight gain. However, it is thought that PHE is not used

This work was supported by European Grant INTERREG IVB SUDOE [Grant 1/P1/E178 to J.M.] "DIOmed Project."

https://doi.org/10.1124/jpet.119.259895. proportionally to its benefits to adverse effects ratio. Benefits include a neuroprotective role, which has been demonstrated after the identification of novel PHE targets (reviewed in Song et al., 2013; Baker et al., 2019), including the chemical sequestration of reactive aldehydes in a manner that seems to be related to the hydrazine structure of PHE (Baker et al., 2019). Moreover, PHE also inhibits histone lysine-specific demethylases and may play a role in epigenetic regulations (Yan et al., 2016). In contrast, the adverse effects have been reconsidered because the risk of hypertensive crisis associated with concomitant high tyramine dietary intake is lower than initially expected. Increased food intake and body weight are

ABBREVIATIONS: AO, amine oxidase; BAT, brown adipose tissue; EE, energy expenditure; eWAT, epididymal WAT; HDL, high-density lipoprotein; HFD, high-fat diet; HSD, high-sucrose drinking; iBAT, interscapular BAT; IL, interleukin; iWAT, inguinal WAT; MAO, monoamine oxidase; NEFA, nonesterified fatty acids; PEPCK, phosphoenolpyruvate carboxykinase; PHE, phenelzine; pWAT, perirenal plus retroperitoneal WAT; QUICKI, quantitative insulin sensitivity check index; RQ, respiratory quotient; SREBP1c, sterol regulatory element-binding protein-1c; SSAO, semicarbazidesensitive amine oxidase; VAP-1, vascular adhesion protein-1; WAT, white adipose tissue. 
unwanted effects reported for many other psychotropic drugs (Zimmermann et al., 2003), such as olanzapine, which impairs lipolysis in adipocytes (Minet-Ringuet et al., 2007). However, in the case of PHE, studies have suggested an antiobesity potential (reviewed in Carpéné et al., 2019), which reinforces the idea that weight gain could be a consequence of the improvement of psychiatric disorders rather than a direct effect (Zimmermann et al., 2003).

PHE's antiobesity potential is attributed to an impairment of lipogenesis (Carpéné et al., 2019). We recently reported that chronic PHE treatment reduces body fat in normal-weight mice without cardiovascular impairment (Carpéné et al., 2018c). Reduced body weight has been observed in a genetic obesity model (Carpéné et al., 2008). This effect was partly attributed to an inhibition of primary amine oxidase, also called semicarbazide-sensitive amine oxidase and vascular adhesion protein-1 (SSAO/VAP-1), a membrane-bound protein abundant in adipocytes involved in the etiology of metabolic and cardiovascular diseases (Pannecoeck et al., 2015). The reduction in fat deposition by semicarbazide administration and SSAO activity (Mercader et al., 2011) implies a reduction in the subsequent hydrogen peroxide $\left(\mathrm{H}_{2} \mathrm{O}_{2}\right)$ production that acts as an insulin-mimetic compound in adipocytes (Zorzano et al., 2003). Accordingly, the antilipogenic action of SSAO inhibitors has been demonstrated (Carpéné et al., 2008, 2013), whereas SSAO substrates enhance glucose transport and lipogenesis via increased $\mathrm{H}_{2} \mathrm{O}_{2}$ in adipocytes (Morin et al., 2001; Zorzano et al., 2003; Iglesias-Osma et al., 2004), and thus have been proposed as a treatment option for diabetes (Mercader et al., 2010). The PHE inhibitory effect on lipid accumulation might involve SSAO-independent targets, including sterol regulatory element-binding protein-1c (SREBP1c) (Chiche et al., 2009) and phosphoenolpyruvate carboxykinase (PEPCK) (Carpéné et al., 2018b,c).

Additionally, PHE might mitigate obesity-associated alterations by acting on key molecular targets in oxidative stress, inflammation, and glucose homeostasis. Excessive fat accumulation triggers oxidative stress that is responsible for the development of insulin resistance and cardiovascular disease (Bashan et al., 2009). Owing to its scavenging activity (Baker et al., 2019), PHE attenuates plasma protein carbonyl groups and lipid peroxidation induced by reactive species (Mustafa et al., 2018a,b) and inhibits carbonyl stress accompanied by a reduction in atherosclerotic lesion (Galvani et al., 2008). Moreover, PHE reduces hepatic lipid peroxidation in highsucrose drinking (HSD) mice (Carpéné et al., 2018b). Therefore, it would be interesting to explore whether PHE inhibits the increased oxidative stress associated with obesity and insulin resistance.

A chronic low-grade inflammation state is a characteristic of obesity in which the recruitment of immune cells in adipose tissue plays a pivotal role in the development of inflammation (Vachharajani and Granger, 2009). SSAO/VAP-1 supports the rolling, adhesion, and migration of leukocytes (Jalkanen and Salmi, 1993; Koskinen et al., 2004). SSAO/VAP-1 inhibitors reduce leukocyte extravasation and the expression of proinflammatory cytokines in experimental models of inflammation other than obesity (Koskinen et al., 2004; Salter-Cid et al., 2005; Wang et al., 2006; O'Rourke et al., 2008; Wang et al., 2018). Therefore, it is plausible that PHE inhibits low-grade inflammation in obese and insulin-resistant states.
The hypoglycemic effect of PHE (McIntyre et al., 2006) may be caused by an inhibition of intestinal glucose uptake, hepatic gluconeogenesis, and alteration of pancreatic insulin release (Aleyassine and Gardiner, 1975; Feldman and Chapman, 1975; Haeckel and Oellerich, 1977; Haeckel et al., 1984). Given glycaemia restoration in HSD mice (Carpéné et al., 2018 b), it becomes challenging to investigate whether PHE influences glucose homeostasis in insulin-resistant models.

To determine whether PHE affects obesity-associated metabolic disturbances, we analyzed its effects on body fat accumulation, markers of oxidative stress and inflammation, and glucose and insulin homeostasis, in a model of diet-induced obesity and insulin resistance.

\section{Materials and Methods}

Animals, Diet, and Treatment. All animal care and experimental procedures complied with the principles established by INSERM, under the permission number 12-1048-03-15, and were approved by the Animal Ethics Committee of the Unit US006 Centre Régional d'Exploration Fonctionelle et Ressources Expérimentales (Toulouse, France).

Male C57BL/6 mice (Charles River, L'Arbresle, France) were housed for at least 2 weeks before treatment, in the INSERM US006 animal facility (three per cage) under 12/12 hour light/dark cycle with controlled temperature $\left(20-22^{\circ} \mathrm{C}\right)$ and humidity (50\%-60\%). Mice were 11 weeks old at the start of the experiment. All animal studies are in compliance with the Animal Research Reporting of In Vivo Experiments guidelines (Kilkenny et al., 2010; McGrath and Lilley, 2015).

The study protocol was not subject to randomization because mice were separated into two groups of 12 with equivalent mean body weight $(28.2 \pm 1.0$ and $28.1 \pm 0.5 \mathrm{~g}) 5$ days before the start of the protocol. On day 0, standard chow (SAFE, Augy, France) was replaced by a high-fat diet (HFD) containing $45 \%$ of the energy from fat (Research Diets, New Brunswick, NJ). Mice received ad libitum either tap water for drinking (HFD), or PHE sulfate in the drinking water for 83 days (HFD + PHE) provided as a $0.028 \%$ solution $(1.20 \mathrm{mM})$, as previously described (Carpéné et al., 2018b,c). Body mass and food and water consumption were recorded twice per week.

In Vivo Determinations on Awake Animals. Nonfasting blood glucose was determined weekly between 15:00 and 16:00 with a glucose monitor (Roche Diagnostic, Mannheim, Germany), using a blood drop withdrawn from the tail. Fasting blood glucose and insulin levels were determined at week 10 of treatment, prior to an oral glucose tolerance test, which was performed after an 8-hour fasting. Mice given a $60 \%$ glucose solution $\left(3 \mathrm{~g} \times \mathrm{kg}^{-1}\right.$ body weight $)$ via oral gavage and glucose levels were determined at times $-30,0,15$, 30, 45, 60, and 120 minutes. Fasting serum insulin levels were assessed by an ultrasensitive mouse insulin ELISA (Mercodia AB, Uppsala, Sweeden). Insulin resistance was calculated by the homeostatic model assessment of insulin resistance $\left[=\right.$ glucose $\left(\mathrm{mmol} \times \mathrm{l}^{-1}\right)$ $\times$ insulin $\left(\mu \mathrm{U} \times 1^{-1}\right) / 22.5$ ], and two surrogate indexes of insulin sensitivity: quantitative insulin sensitivity check index $($ QUICKI $)=1 /$ $\log$ glucose $\left(\mathrm{mg} \times \mathrm{dl}^{-1}\right)+\log$ insulin $\left(\mu \mathrm{U} \times \mathrm{ml}^{-1}\right)+\log$ nonesterified fatty acids (NEFA, mmol $\times \mathrm{l}^{-1}$ ) and revised QUICKI $=1 / \log$ glucose $\left(\mathrm{mg} \times \mathrm{dl}^{-1}\right)+\log$ insulin $\left(\mu \mathrm{U} \times \mathrm{ml}^{-1}\right)+\log \mathrm{NEFA}\left(\mathrm{mmol} \times \mathrm{l}^{-1}\right)$, as previously described (Matthews et al., 1985; Katz et al., 2000; Perseghin et al., 2001). $\Delta \mathrm{I} / \Delta \mathrm{G}$ score was assessed as a glucose sensitivity index and calculated by measuring insulin and glucose concentrations 30 minutes before and 15 minutes after the oral glucose load.

Body composition was assessed at weeks 6,8 , and 11 of treatment by nuclear NMR with an EchoMRI 100 3-in-1 device (Echo Medical Systems, Houston, TX).

Rectal temperature was measured within the first 4 hours of the light cycle using a digital thermometer (Hanna Instruments, Woonsocket, RI). 
Indirect calorimetry was performed in six mice per group after 24 hours of acclimatization in individual cages at week $8 . \mathrm{O}_{2}$ consumption $\left(\mathrm{VO}_{2}\right)$ and $\mathrm{CO}_{2}$ production $\left(\mathrm{VCO}_{2}\right)$ were measured (Oxylet; Panlab-Bioseb) in individual mice at 25-minute intervals during a 24-hour period. The respiratory quotient $\left(\mathrm{RQ}=\mathrm{VCO}_{2} / \mathrm{VO}_{2}\right)$ and energy expenditure [EE, in kcal $\times$ day $^{-1} \times \mathrm{kg}^{-1}, 0.75=1.44 \times$ $\left.\mathrm{VO}_{2} \times(3.815+1.232 \times \mathrm{RQ})\right]$ were calculated. Ambulatory activities of the mice were monitored by an infrared photocell beam interruption method (Sedacom; Panlab-Bioseb).

Tissue Collection and Composition Analysis. Mice were sacrificed by cervical dislocation after overnight fasting. Troncular blood was collected in heparinized tubes and processed to obtain plasma samples. White adipose tissue (WAT) was dissected from subcutaneous inguinal WAT (iWAT) and visceral epididymal WAT (eWAT) and retroperitoneal plus perirenal WAT (pWAT) anatomic locations, whereas brown adipose tissue (BAT) was dissected from the interscapular BAT (iBAT). Adiposomatic index was calculated as the percentage of the sum of dissected fat pads relative to body mass.

Fat pads, liver, heart, and skeletal muscles from the hind leg were weighed, snap-frozen in liquid nitrogen, and stored at $-80^{\circ} \mathrm{C}$ until analysis. Portions of iWAT, eWAT, pWAT, and liver were also immediately processed to determine $\mathrm{H}_{2} \mathrm{O}_{2}$ release, lipogenesis, and lipolysis. Tissue lipid content was assessed using the Dole method, as in Dole and Meinertz (1960). Tissue DNA content was fluorimetrically quantified using DNA from salmon testes as standard (Sigma-Aldrich, St. Louis, MO). Tissue protein content was assessed with the bicinchoninic acid protein assay kit (Pierce, Rockford, IL).

Spontaneous $\mathrm{H}_{2} \mathrm{O}_{2}$ Release and Amine Oxidase Activity. The spontaneous release of $\mathrm{H}_{2} \mathrm{O}_{2}$ by pieces of iWAT pad was immediately measured after sacrifice by using the fluorimetric Amplex Red method, as previously described (Carpéné et al., 2016). This method relies on the horseradish peroxidase-catalyzed production of resorufin from 10-acetyl-3,7 dihydrophenoxazine and $\mathrm{H}_{2} \mathrm{O}_{2}$. Briefly, $30 \mathrm{mg}$ fresh intact iWAT pad pieces were incubated with the chromogenic mixture of $40 \mu \mathrm{M}$ Amplex Red (Interchim, Montluçon, France) plus $4 \mathrm{U} / \mathrm{ml}$ horseradish peroxidase in phosphate buffer at $\mathrm{pH}$ 7.5. The $\mathrm{H}_{2} \mathrm{O}_{2}$ release was measured without any addition (spontaneous release), with $0.1 \mathrm{mM}$ benzylamine (SSAO substrate), or with $0.1 \mathrm{mM}$ benzylamine after $1 \mathrm{mM}$ semicarbazide preincubation (to measure SSAO activity). After 30 minutes of incubation, samples were excited at $544 \mathrm{~nm}$ and fluorescence readouts at $590 \mathrm{~nm}$ were collected with the Fluoroskan Ascent microplate reader (ThermoLabsystems, Vantaa, Finland). To verify that the spontaneous release of $\mathrm{H}_{2} \mathrm{O}_{2}$ in iWAT was increased by HFD, we also measured it in 12 normal-weight male C57BL/6 mice of the same age (5 months old) fed a standard chow (control, CON).

SSAO and MAO activities were similarly determined in thawed iWAT and liver homogenates with slight modifications (Zhou and Panchuk-Voloshina, 1997). Tissue homogenates were incubated in the presence of $0.5 \mathrm{mM}$ tyramine or $0.1 \mathrm{mM}$ benzylamine, with or without preincubation with $0.1 \mathrm{mM}$ pargyline (to determine MAO component) or $1 \mathrm{mM}$ semicarbazide (for SSAO component). $\mathrm{H}_{2} \mathrm{O}_{2}$ release was normalized to the protein content of the homogenate.

Lipogenesis and Lipolysis. Adipocytes were isolated from eWAT and pWAT pads by digestion with $15 \mu \mathrm{g} \times \mathrm{ml}^{-1}$ type TM liberase (Roche Diagnostics, Meylan, France) in Krebs-Ringer buffer supplemented with $15 \mathrm{mM}$ bicarbonate, $10 \mathrm{mM}$ HEPES, $2 \mathrm{mM}$ pyruvate, and $3.5 \%$ bovine serum albumin (KRBH buffer), at $37^{\circ} \mathrm{C}$ for 45 minutes. Once the tissue was digested, filtered, and washed, lipogenesis was assessed as the radioactively labeled glucose incorporated into cellular lipids, as previously described (Harant-Farrugia et al., 2014). Briefly, adipocytes were incubated with a mixture of cold glucose and D-[3- $\left.{ }^{3} \mathrm{H}\right]$-glucose (PerkinElmer, Waltham, MA) for 120 minutes at $37^{\circ} \mathrm{C}$ in the absence or presence of $0.1 \mu \mathrm{M}$ insulin, $0.1 \mathrm{mM}$ benzylamine, $0.1 \mathrm{mM}$ vanadate, or $0.1 \mathrm{mM}$ benzylamine plus $0.1 \mathrm{mM}$ vanadate. Reactions were stopped by adding sulfuric acid, and radioactivity was measured after adding a nonwater-miscible liquid scintillation cocktail (InstaFluor-plus; PerkinElmer). Cell lipid content was extracted and quantified, as described above.

Lipolytic activity was assessed by glycerol release, as previously reported (Carpéné et al., 2007). Briefly, adipocytes were diluted $10 \times$ in $\mathrm{KRBH}$ buffer. Samples at a final volume of $0.4 \mathrm{ml}$ were incubated for 90 minutes in the absence or presence of $1 \mu \mathrm{M}$ isoprenaline or $1 \mu \mathrm{M}$ isoprenaline plus $1 \mathrm{mM}$ tyramine. Glycerol released was referred to $100 \mathrm{mg}$ cellular lipids.

Gene Expression. Total RNA was isolated from iWAT, pWAT, iBAT, liver, and skeletal muscle, following the chloroform/isopropanol method using Qiazol (Qiagen, Hilden, Germany) to homogenize tissues. RNA was reverse transcribed using Superscript II reverse transcriptase (Life Technologies, Carlsbad, CA) and random hexamers. Real-time polymerase chain reaction was performed in a Step One Plus system (Applied Biosystems, Warrington), using the SYBR Green Master Mix (Eurogentec, Liège, Belgium). Oligonucleotide primers were designed and are available upon request. Relative gene expression was calculated using the $2^{-\Delta \Delta \mathrm{Ct}}$ method with $18 \mathrm{~S}$ ribosomal RNA as internal control.

Oxidative Stress-Related Parameters. Aconitase activity was measured with a spectrophotometric assay (OxisResearch, Foster City, CA). Lipid peroxidation was determined by measuring the formation of malondialdehyde, with a thiobarbituric acid reactive substances assay kit (Cayman Chemical, Ann Arbor, MI).

Other Circulating Parameters. Fasting NEFAs, triacylglycerols, low-density lipoprotein cholesterol, high-density lipoprotein (HDL) cholesterol, phosphatase alkaline, alanine aminotransferase, and urea plasma levels were determined by using an autoanalyzer (Cobas Roche Diagnostic, Basel, Switzerland). Fasting circulating glycerol was determined by using an enzymatic colorimetric kit (Sigma-Aldrich, Saint-Quentin-Fallavier, France).

Data and Statistical Analysis. The data and statistical analysis comply with the recommendations on experimental design and analysis in pharmacology (Curtis et al., 2018). Normal distribution of the data was tested using the Shapiro-Wilk test. Log transformation was applied before the analysis if variables were not adjusted to parametric criteria. Data are given as mean \pm S.E.M. of the indicated number of independent observations and were analyzed comparing two experimental groups by Student's $t$ test or Mann-Whitney $U$ test for parametric and nonparametric distributions, respectively. Twoway repeated measures ANOVA followed by a Bonferroni post hoc test were used for multiple measures analysis. Statistical significance was assumed when $P<0.05$. Calculations were made with IBM SPSS Statistics, version 25.0 (IBM, Armonk, NY), and were represented with GraphPad Prism version 8.0.0.

Materials. PHE sulfate (P6777 from Sigma-Aldrich-Merck) was dissolved weekly in tap water to provide enough drinking solution to the treated mice. Most of the other reagents were from Sigma-AldrichMerck, unless otherwise stated. Isoprenaline, identical to (-)-isoproterenol, was a generous gift from A. Mairal (I2MC, Toulouse, France).

\section{Results}

Oral Chronic PHE Treatment Reduces Body Adiposity in HFD Mice. HFD + PHE mice showed a lower body weight than HFD mice as early as the first week of treatment (Fig. 1A). This difference was maintained throughout most of the treatment, and, by the end of it, HFD + PHE mice weighed $11 \%$ less versus HFD. These differences could not be explained by decreased food consumption (Fig. 1B) or lean tissue hydration (data not shown). Consequently, energy efficiency was lower in HFD + PHE (Fig. 1C).

However, body weight reduction could be attributable to reduced body fat content, which was $29 \%, 27 \%$, and $20 \%$ lower at weeks 6,8 , and 11, respectively (Fig. 1D). PHE treatment differentially affected the weight and lipid content of the 

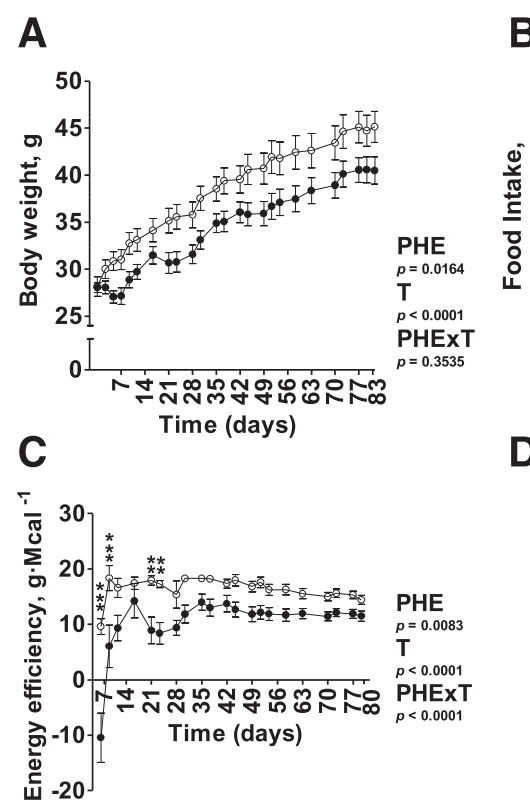
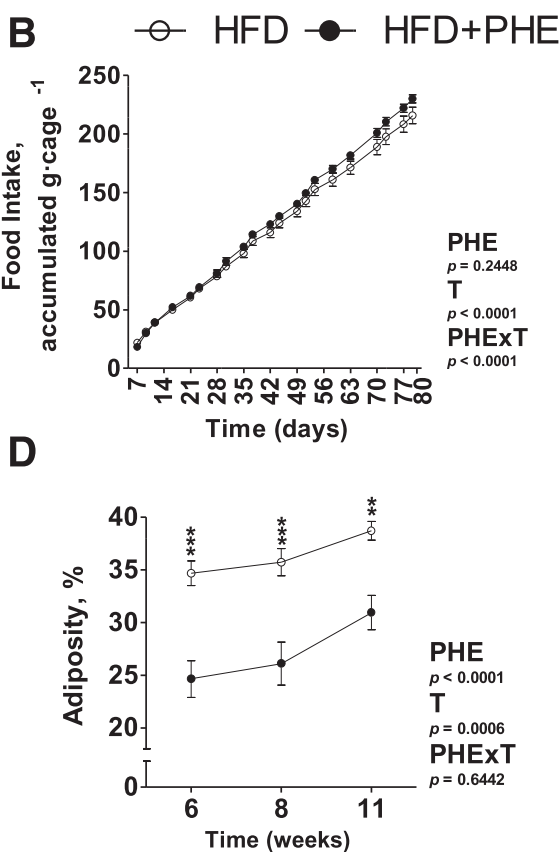

Fig. 1. Effects of chronic PHE treatment on body weight and energy efficiency in C57BL/6 male mice. (A) Body weight evolution, (B) food intake accumulation, (C) energy efficiency, and (D) adiposity index during the 11 weeks of the treatment. Data are mean \pm S.E.M. of 12 animals per group, except in the case of food intake, which was calculated on a per-cage basis and are the mean \pm S.E.M. of four cages per group (three animals/cage). Two-way repeated measures ANOVA, followed by a Bonferroni post hoc test, was performed to compare the different effects of treatment and time $(* * P<0.01 ; * * * P<0.001)$. PHE, treatment effect; $\mathrm{T}$, time effect; and PHE $\times \mathrm{T}$, interactive effect between treatment and time. distinct fat pads, particularly in subcutaneous pads. The weights of iWAT and iBAT were lower, whereas those of eWAT and pWAT were unchanged (Table 1). The adiposomatic index was not significantly reduced in HFD + PHE mice $(P=0.157)$. Tissue composition analysis revealed that, in line with pad weights, total lipid content was reduced in iWAT and iBAT of HFD + PHE mice. In addition, DNA content in both iWAT and eWAT, as well as protein content in the eWAT, was lower in HFD + PHE mice, suggesting that the number of cells could be reduced by PHE in iWAT and, despite the lack of differences in total lipid content and pad weight, also in eWAT (Table 1). Interestingly, the antifattening effect of PHE treatment was evidenced ectopically, in accordance with previous observations (Carpéné et al., 2018b,c). Thus, lipid content in liver and skeletal muscle was, respectively, $58 \%$ and $34 \%$ lower in HFD + PHE animals (Table 1 ).

Importantly, PHE treatment normalized the circulating levels of alanine aminotransferase (HFD: $76.5 \pm 13.2 \mathrm{U} \times \mathrm{l}^{-1}$; HFD + PHE: $\left.32.7 \pm 4.7 \mathrm{U} \times 1^{-1}, P<0.01\right)$ and alkaline phosphatase (HFD: $24.8 \pm 3.3 \mathrm{U} \times 1^{-1}$; HFD + PHE: $14.8 \pm$ $\left.2.5 \mathrm{U} \times \mathrm{l}^{-1}, P<0.05\right)$. Lack of increase in transaminase concentration, together with unaltered circulating urea levels (HFD: $7.6 \pm 0.3 \mathrm{mM}$; HFD + PHE: $7.9 \pm 0.5 \mathrm{mM}, P=0.591$ ), indicated that this treatment was not hepato- or nephrotoxic.

Adipose and Hepatic SSAO and MAO Activities Are Inhibited by PHE Treatment. The calculated daily PHE intake was $20.8 \pm 1.6 \mathrm{mg}(88.9 \pm 6.7 \mu \mathrm{mol})$ per kilogram of body weight. It was estimated from previous experiments in normal-weight mice that chronic exposure to a $1.2 \mathrm{mM}$ PHE drinking solution could inhibit adipose SSAO and MAO activities in mice fed a HFD (Carpéné et al., 2018c). amine oxidase (AO) activities were measured to confirm they were inhibited. As expected, benzylamine and, to a lesser extent, tyramine were preferentially oxidized by SSAO rather than MAO in iWAT homogenates (Fig. 2, A and B). Collectively, total benzylamine oxidation was inhibited by $83 \%$ in iWAT homogenates of HFD + PHE mice (Fig. 2A). PHE treatment almost completely blocked benzylamine oxidation by SSAO activity (by 82\%) and reduced MAO activity to negligible levels. Similarly, PHE treatment inhibited the tyramine oxidation by SSAO (80\%), MAO (89\%), and both AO (79\%) activities (Fig. 2B).

In liver homogenates, tyramine and benzylamine were more oxidized by MAO than by SSAO (Fig. 2, C and D). PHE

TABLE 1

Influence of PHE chronic treatment on biometric and tissue composition parameters in mice fed a HFD

Eleven-week-old C57BL/6 male mice on a HFD received water or $88.9 \mu \mathrm{mol} \mathrm{PHE} / \mathrm{kg}$ body weight per day to drink (HFD + PHE) for 11 wk. Data are the mean \pm S.E.M. of $n=12$ /group. A Student's $t$ test was performed. Difference HFD vs. HFD + PHE mice.

\begin{tabular}{|c|c|c|}
\hline Parameter & HFD & HFD + PHE \\
\hline $\begin{array}{l}\text { Adiposomatic index (\%) } \\
\text { iWAT }\end{array}$ & $12.1 \pm 0.5$ & $10.8 \pm 0.7$ \\
\hline $\operatorname{Mass}(\%)$ & $4.46 \pm 0.13$ & $3.36 \pm 0.26^{* *}$ \\
\hline Lipid (mg/pad) & $1417 \pm 124$ & $929 \pm 116^{* *}$ \\
\hline Protein $(\mathrm{mg} / \mathrm{pad})$ & $20.8 \pm 2$ & $17.4 \pm 1.9$ \\
\hline $\begin{array}{l}\text { DNA ( } \mu \mathrm{g} / \mathrm{pad}) \\
\text { eWAT }\end{array}$ & $142 \pm 16$ & $95 \pm 7^{*}$ \\
\hline Mass $(\%)$ & $5.24 \pm 0.42$ & $5.35 \pm 0.37$ \\
\hline Lipid (mg/pad) & $1924 \pm 128$ & $1727 \pm 189$ \\
\hline Protein $(\mathrm{mg} / \mathrm{pad})$ & $25.9 \pm 1.8$ & $20.1 \pm 1.9^{*}$ \\
\hline $\begin{array}{l}\text { DNA ( } \mu \mathrm{g} / \mathrm{pad}) \\
\text { iBAT }\end{array}$ & $251 \pm 13$ & $200 \pm 16^{*}$ \\
\hline Mass (\%) & $0.51 \pm 0.03$ & $0.041 \pm 0.03 *$ \\
\hline Lipid (mg/pad) & $147 \pm 14$ & $92 \pm 10^{* *}$ \\
\hline Protein (mg/pad) & $12.8 \pm 0.6$ & $12.3 \pm 0.5$ \\
\hline $\begin{array}{l}\text { DNA ( } \mu \mathrm{g} / \mathrm{pad}) \\
\text { pWAT }\end{array}$ & $15 \pm 0.9$ & $12.8 \pm 0.9$ \\
\hline $\begin{array}{l}\text { Mass }(\%) \\
\text { Liver }\end{array}$ & $1.85 \pm 0.08$ & $1.72 \pm 0.11$ \\
\hline Mass $(\%)$ & $3.87 \pm 0.2$ & $3.73 \pm 0.16$ \\
\hline Lipid (mg/pad) & $274 \pm 58$ & $116 \pm 28^{*}$ \\
\hline Protein $(\mathrm{mg} / \mathrm{pad})$ & $290 \pm 28$ & $252 \pm 15$ \\
\hline $\begin{array}{l}\text { DNA ( } \mu \mathrm{g} / \mathrm{pad}) \\
\text { Skeletal muscle }\end{array}$ & $1707 \pm 161$ & $1396 \pm 175$ \\
\hline $\begin{array}{l}\text { Skeletal muscle } \\
\text { Lipid (mg/g tissue) } \\
\text { Heart }\end{array}$ & $16.1 \pm 1.8$ & $10.7 \pm 0.8^{*}$ \\
\hline Mass $(\%)$ & $0.42 \pm 0.02$ & $0.41 \pm 0.01$ \\
\hline
\end{tabular}




\section{Benzylamine oxidation in iWAT}

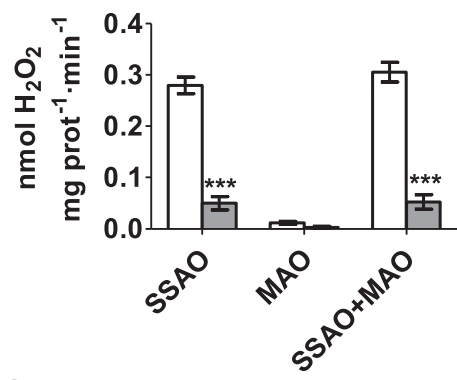

C

Benzylamine oxidation in liver

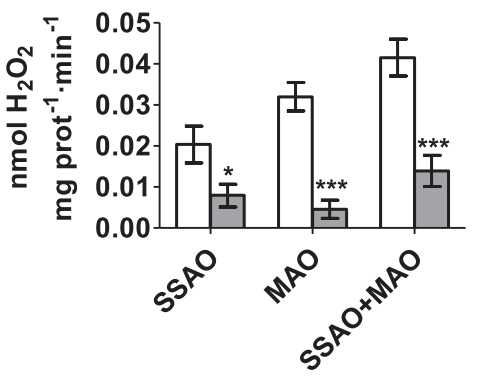

E

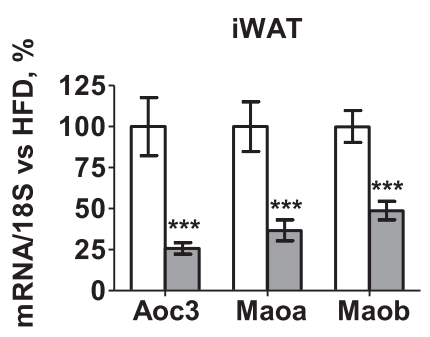

B $\square \mathrm{HFD} \square \mathrm{HFD}+\mathrm{PHE}$

Tyramine oxidation in iWAT

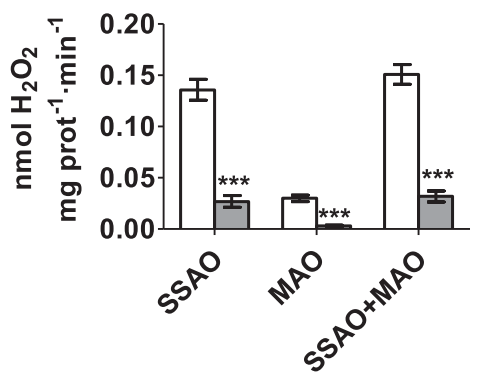

D

Tyramine oxidation in liver

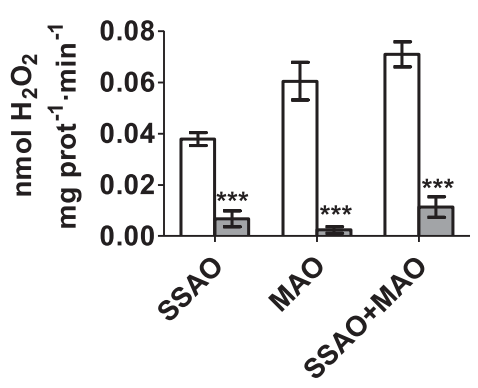

Fig. 2. Influence of chronic $\mathrm{PHE}$ treatment on adipose and hepatic SSAO and MAO activities in C57BL/6 male mice. (A) $0.1 \mathrm{mM}$ benzylamine oxidation and (B) $0.5 \mathrm{mM}$ tyramine oxidation in iWAT by SSAO, MAO, and SSAO + MAO; (C) $0.1 \mathrm{mM}$ benzylamine and (D) $0.5 \mathrm{mM}$ tyramine oxidation in liver by SSAO, MAO, and SSAO + MAO; and (E) mRNA levels of Aoc3, Maoa, and Maob in iWAT and (F) in liver. Data are mean \pm S.E.M. of 9 to 10 (amine oxidase activities) or 12 (gene expression) animals per group. Student's $t$ test was used for the analysis $(* P<0.05$; $* * P<0.01$; $* * * P<0.001)$

F

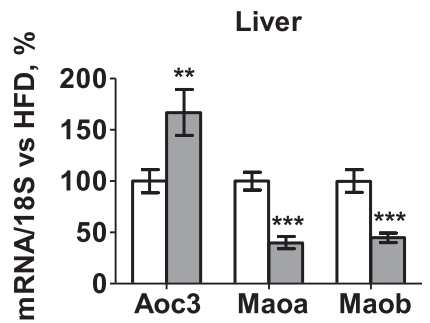

treatment inhibited benzylamine oxidation by $\mathrm{MAO}(86 \%)$ and SSAO (61\%) activities, and total benzylamine oxidation was reduced by $66 \%$ (Fig. 2C). Likewise, treatment inhibited tyramine oxidation by MAO (96\%), SSAO (82\%), and both (84\%) activities (Fig. 2D).

To further explore the mechanism of SSAO and MAO regulation by $\mathrm{PHE}$, we analyzed whether it regulates $\mathrm{AOs}$ at the transcriptional level. Hence, we determined the mRNA expression of Aoc3, the gene that encodes SSAO and MAO isoforms, MAO-A and MAO-B, in iWAT and liver. Aoc3, Maoa, and $M a o b$ mRNA levels were all reduced in iWAT, indicating that $\mathrm{PHE}$ regulates SSAO and MAO at the transcriptional level in adipose tissue (Fig. 2E). Similarly, in liver, Maoa and $M a o b$ mRNA levels were reduced, whereas Aoc3 mRNA levels were increased, suggesting opposing mechanisms for SSAO regulation in the liver (Fig. $2 \mathrm{~F}$ ).

PHE Inhibits Lipid Metabolism Genes and Reduces Amine-Induced Lipogenesis and Antilipolysis in Adipocytes. We investigated the potential effect of PHE treatment on the expression of key genes in lipid biosynthesis in HFD mice, particularly of those shown to be regulated by PHE (Chiche et al., 2009; Carpéné et al., 2018b,c), in pWAT, iWAT, iBAT, and liver (Fig. 3A). Peroxisome proliferator-activated receptor $\gamma 2$ is the master regulator of adipocyte differentiation that transcriptionally controls the genes involved in lipid biosynthesis and uptake. In HFD + PHE mice, Pparg2 mRNA levels were reduced in pWAT and iWAT by $34 \%$ and $66 \%$, respectively. SREBP1c is a transcription factor that controls the expression of lipogenic genes, such as fatty acid synthase (Fas). Srebp 1c mRNA levels were lower in iWAT (61\%), iBAT (29\%), and liver (49\%), whereas Fas mRNA levels were reduced in iWAT $(75 \%)$ and liver $(71 \%)$ of HFD + PHE mice. Lastly, PEPCK is a key enzyme in adipose fatty acid reesterification, and mRNA levels were reduced in iWAT $(39 \%)$, and in liver $(30 \%)$.

De novo lipogenesis has been shown to be impaired in isolated adipocytes acutely treated with PHE (Carpéné et al., 2013) and in adipocytes from mice chronically exposed to an oral solution of PHE (Carpéné et al., 2018c). PHE treatment did not affect basal or $100 \mathrm{nM}$ insulin-stimulated glucose incorporation into lipids and did not alter the modest responses to $100 \mu \mathrm{M}$ benzylamine or $100 \mu \mathrm{M}$ vanadate (Fig. 3B). However, in the presence of $100 \mu \mathrm{M}$ benzylamine plus $100 \mu \mathrm{M}$ vanadate, only the HFD group exhibited a stimulation of glucose incorporation into lipids.

To investigate whether lipid mobilization was involved in the adiposity reduction observed, we first analyzed the expression of the hormone-sensitive lipase, one of the major components of the lipolytic cascade, and found that mRNA levels were lower in the iWAT of PHE-drinking mice (Fig. 3A). 


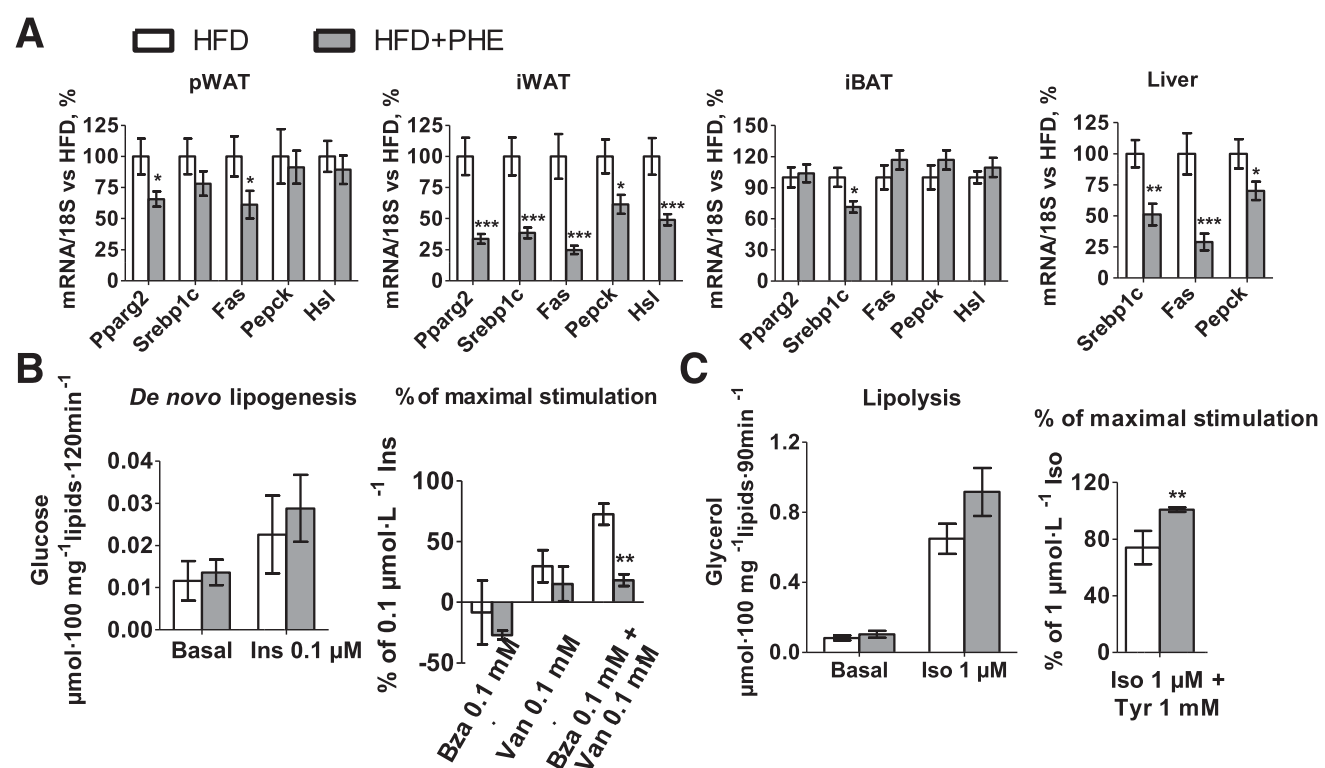

Fig. 3. Effects of chronic PHE treatment on adipose lipid metabolism in C57BL/6 male mice. (A) Gene expression of Pparg2 (peroxisome proliferatoractivated receptor $\gamma 2$ ), Srebp1c (sterol regulatory element-binding protein-1c), Fas (fatty acid synthase), Pepck (phosphoenolpyruvate carboxykinase), and $\mathrm{Hsl}$ (hormone-sensitive lipase) in pWAT, iWAT, iBAT, and liver. (B) Glucose incorporation as a measure of de novo lipogenesis in visceral adipocytes when incubated with insulin, benzylamine (Bza), vanadate (Van), and a combination of Bza + Van. (C) Basal, isoprenaline (Iso), and Iso + tyramine (Tyr) lipolysis in the adipocytes. Data are mean \pm S.E.M. of five (lipogenesis) or eight (lipolysis) animals per group. Student's $t$ test was used for the analysis $(* P<0.05 ; * * P<0.01 ; * * * P<0.001)$.

Then we assessed the potential effect of chronic PHE treatment on the lipolytic action of isoprenaline in visceral adipocytes. Neither basal- nor $1 \mu \mathrm{M}$ isoprenaline-stimulated glycerol release was affected by PHE (Fig. 3C). Furthermore, we assessed the antilipolytic action of tyramine on isoprenaline-induced lipolysis. As expected, the antilipolytic action of $1 \mathrm{mM}$ tyramine was observed in HFD mice in which isoprenaline-induced lipolysis was reduced by $26 \%$. On the contrary, the antilipolytic effect of tyramine was not evidenced in HFD + PHE mice. Based on our previous observations of the AO dependency of the antilipolytic effect of tyramine (Carpéné et al., 2018a), it is likely that the inhibition of adipose AO activity in HFD + PHE induces the disappearance of such tyramine effect in their adipocytes.

PHE Reduces $\mathrm{H}_{2} \mathrm{O}_{2}$ Production in Fresh iWAT. First, we verified that the spontaneous release of $\mathrm{H}_{2} \mathrm{O}_{2}$ by freshly isolated iWAT was increased by HFD. $\mathrm{H}_{2} \mathrm{O}_{2}$ release in HFD mice was 3-fold higher than in standard chow-fed mice (HFD vs. $\mathrm{CON}: 0.127 \pm 0.018$ vs. $0.040 \pm 0.009 \mathrm{nmol} \mathrm{H}_{2} \mathrm{O}_{2} / \mathrm{min}$ per milligram protein; $P<0.001$ ), confirming that HFD increases oxidative stress in adipose tissue (Sonta et al., 2004). Remarkably, the spontaneous release of $\mathrm{H}_{2} \mathrm{O}_{2}$ relative to protein content or tissue weight was reduced in HFD + PHE mice by $59 \%$ and $37 \%$, respectively (Fig. $4 \mathrm{~A}$ ). In response to $100 \mu \mathrm{M}$ benzylamine, $\mathrm{H}_{2} \mathrm{O}_{2}$ levels tended to increase in HFD mice, whereas they remained low in HFD + PHE mice, suggesting that the AO-produced $\mathrm{H}_{2} \mathrm{O}_{2}$ was blocked. The preincubation of $1 \mathrm{mM}$ semicarbazide with iWAT allowed us to estimate SSAO activity, and, in accordance with the assays performed in iWAT homogenates, we confirmed that SSAO activity was almost abolished by PHE treatment (HFD vs. HFD + PHE: $0.208 \pm 0.057$ vs. $0.055 \pm 0.018 \mathrm{nmol} \mathrm{H}_{2} \mathrm{O}_{2} /$ min per milligram protein; $P<0.05$ ).

Markers of oxidative stress in other tissues were not modified by treatment, including hepatic and plasma malondialdehyde levels (Fig. 4B) and hepatic and cardiac aconitase activity (Fig. 4C)

PHE Reduces the Expression of InflammatoryRelated Genes in WAT and Liver. We hypothesized that PHE treatment inhibits low-grade inflammation in HFD mice because it potently inhibits SSAO/VAP-1 activity (Carpéné et al., 2008) and SSAO/VAP-1 deficiency reduces leukocyte infiltration in adipose tissue (Bour et al., 2009). To investigate it, we analyzed the expression of genes involved in immune cell infiltration, namely monocyte chemoattractant protein 1 (Mcp1), Cd45, and $F 4 / 80$, and proinflammatory cytokines, namely interleukin (IL)-6, IL10 , and tumor necrosis factor- $\alpha$, in adipose tissue and liver (Fig. 5). In the pWAT, PHE reduced the mRNA levels of Mcp 1 by $50 \%, C d 45$ by $54 \%, I l 6$ by $57 \%$, and $T n f$ by $43 \%$, whereas $F 4 / 80$ and $I l 10$ mRNA levels showed a tendency to decrease. In the iWAT, $C d 45$ mRNA levels were also reduced in HFD + PHE mice by $57 \%$, and Tnf mRNA levels showed a tendency to decrease. In the liver, PHE administration also reduced the mRNA levels of the proinflammatory cytokines $\operatorname{Tnf}(58 \%)$ and $\mathrm{Il6}(75 \%)$.

PHE Treatment Improves Circulating Lipid Profile. We analyzed whether body adiposity mitigation in HFD + PHE mice could be accompanied by changes in the circulating lipid profile. Plasma NEFA levels were elevated in HFD mice, but PHE treatment did not modify them (Fig. 6A). Plasma glycerol and triacylglycerol levels were both reduced in HFD + PHE mice by $30 \%$ and $16 \%$, respectively. Regarding circulating cholesterol levels, there were no differences in low-density lipoprotein cholesterol, whereas HDL cholesterol levels were $12 \%$ lower in HFD + PHE. The unexpected reduction in the circulating levels of HDL cholesterol prompted us to investigate whether PHE treatment triggered any alteration in the expression of a key gene in HDL cholesterol uptake into cells, scavenger receptor class B type 1 


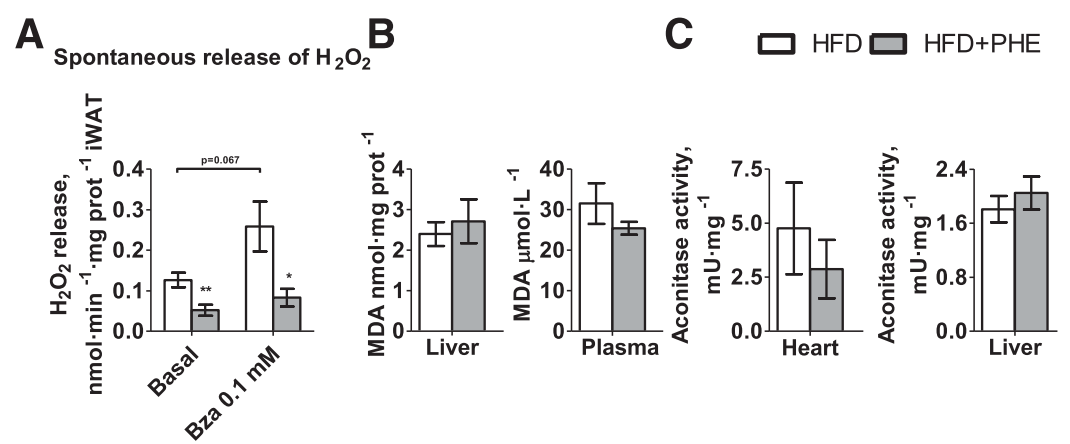

Fig. 4. Effects of chronic PHE treatment on oxidative stress markers in C57BL/6 male mice. (A) Spontaneous release of $\mathrm{H}_{2} \mathrm{O}_{2}$ by fresh pieces of iWAT, (B) Malondialdehyde (MDA) levels in plasma and liver, and (C) aconitase activity in heart and liver. Data are mean \pm S.E.M. of 6 $\left(\mathrm{H}_{2} \mathrm{O}_{2}\right.$ release) or 12 (malondialdehyde levels and aconitase activity) animals per group. Student's $t$ test was used for the analysis $(* P<0.05 ; * * P<0.01)$.
(Sr-b1). Consistent with decreased HDL cholesterol levels, mRNA levels of $S r b 1$ in the liver were $38 \%$ lower in HFD + PHE mice (Fig. 6B).

PHE Reduces Insulinemia without Affecting Glycaemia. No reduction in nonfasting glycaemia was observed in the weekly determinations during treatment in HFD + PHE mice (data not shown). Fasting glycaemia was not changed by treatment, whereas insulinemia was markedly reduced by 55\% (Fig. 7A). Homeostatic model assessment of insulin resistance score indicated that HFD mice developed insulin resistance, whereas in HFD + PHE animals it was found to be 59\% lower, suggesting less insulin resistance (Fig. 7B). This was also supported by QUICKI and revised QUICKI indexes, both $10 \%$ higher in HFD + PHE mice. $\Delta \mathrm{I} / \Delta \mathrm{G}$ score was lower in HFD + PHE mice, suggesting an increased insulin response to glucose (Fig. 7B). However, there were no differences in glucose tolerance after the oral glucose load (Fig. 7C).

PHE Triggers Signs of Higher EE, Despite No Major Impact on Oxidative Metabolism Capacity. An increased half-life of catecholamine and trace amine levels can be expected after a chronic MAO inhibition, which, in turn, could impact oxidative metabolism and thus be involved in the mitigation of the HFD-induced metabolic disturbances. To investigate whether PHE treatment influences oxidative metabolism in HFD mice, we assessed rectal temperature, $\mathrm{EE}$, and locomotor activity.

Rectal temperature was higher in HFD + PHE versus HFD mice (Fig. $8 \mathrm{~A}$ ). $\mathrm{VO}_{2}, \mathrm{VCO}_{2}, \mathrm{RQ}$, and $\mathrm{EE}$ were also higher in HFD + PHE mice at certain time points, according to Student's $t$ test, particularly during the first part of the night period. However, there were no significant differences in any of these parameters after two-way repeated measures ANOVA or when considering the mean values of these data collected within the diurnal, night, or 24-hour periods (Fig. 8, B-E), only a tendency to higher $\mathrm{VCO}_{2}$ and $\mathrm{EE}$. Furthermore, there were no differences regarding the circadian activity (Fig. $8 \mathrm{~F}$ ) and the number of rears (data not shown).
To gain insight into the potential PHE effect on EE, the expression of genes involved in fuel utilization and thermogenesis was analyzed in iBAT, liver, and skeletal muscle (Table 2). In the iBAT, carnitine palmitoyltransferase 1B (Cpt1b) mRNA levels were increased by $22 \%$ in HFD + PHE mice. Vegf expression, which is upregulated under BAT activation, tended to increase in HFD + PHE mice. However, Ppar $\alpha$ (Ppara), Ppar coactivator $\gamma 1 \alpha$ (Ppargc1a), forkhead box $\mathrm{C} 2$ (Foxc2), and uncoupling protein 1 (Ucp1) mRNA levels were unchanged. Hepatic acetyl carboxylase $2(A c c 2)$ and Ppara mRNA levels were reduced $(47 \%$ and $52 \%$, respectively), suggesting opposing effects on lipid catabolism. In skeletal muscle, cluster of differentiation $36(C d 36)$ and uncoupling protein $3(U c p 3)$ mRNA levels were not affected by treatment, whereas those of Ppargc1a and glucose transporter 4 (Glut4) tended to decrease, and those of Ppara and $C p t 1 b$ were even reduced, by $31 \%$ and $25 \%$, respectively.

\section{Discussion}

In this study, we demonstrated that oral chronic PHE treatment reduces metabolic alterations developed by a HFD in mice, including subcutaneous and hepatic fat, hypertriglyceridemia, insulin resistance, and markers of oxidative stress, leukocyte infiltration, and inflammation. Moreover, this animal model has allowed us to further determine factors and molecular mechanisms involved in the metabolic effects of PHE, particularly on fat accumulation, comparing with the effects on other animal models (Carpéné et al., 2008, 2018b). Thus, reduced adiposity by different PHE treatments has been demonstrated in female obese Zucker rats and male mice on a HSD, showing differing results regarding the adipose tissues affected and the mechanisms involved. Only subcutaneous fat pads were decreased in mice on a HFD (present study) or HSD (Carpéné et al., 2018b), whereas visceral fat pads were the only ones decreased in obese Zucker rats (Carpéné et al., 2008). This suggests that
A

PWAT

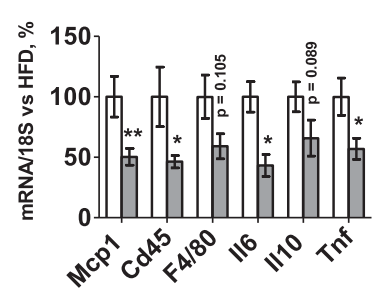

B

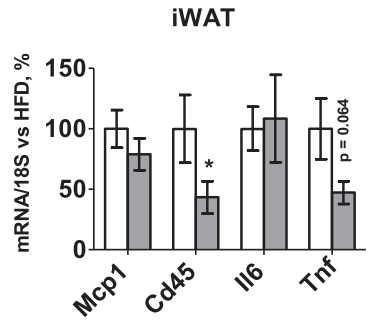

\section{Cロ HFD $\square$ HFD+PHE}

Liver

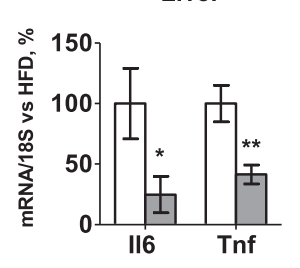

Fig. 5. Effects of chronic PHE treatment on inflammatory markers on C57BL/6 male mice. (A) Mcp 1 (monocyte chemoattractant protein 1), Cd45 (cluster of differentiation 45), F4/80, Il6, $I l 10$, and Tnf mRNA levels in pWAT. (B) Mcp1, $C d 45, I l 6$, and Tnf mRNA levels in iWAT. (C) Il6 and Tnf hepatic mRNA levels. Data are mean \pm S.E.M. of 12 animals per group. Student's $t$ test was used for the analysis $\left({ }^{*} P<0.05 ; * * P<0.01\right)$. 


\section{A $\square$ HFD $\square$ HFD+PHE}
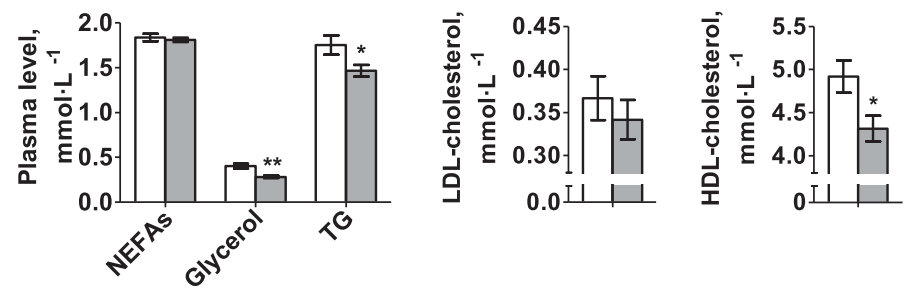

several factors, including diet, species, sex, or drug administration route, could explain the depot-specific impact of PHE on fat stores. According to our results, the limitation of adiposity could be partly attributed to a blockade of SSAO activity associated with an inhibition of amine-induced de novo lipogenesis (Carpéné et al., 2008). The involvement of SSAO inhibition on reducing fat accumulation has been previously demonstrated by the use of other SSAO inhibitors, including semicarbazide (Carpéné et al., 2008; Mercader et al., 2011) and aminoguanidine (Prévot et al., 2007), both showing a lower potency on SSAO inhibition than PHE (Carpéné et al., 2008). On the contrary, our data do not support a major role in lipid mobilization because of the following: 1) plasma NEFA and glycerol did not increase; 2)
B

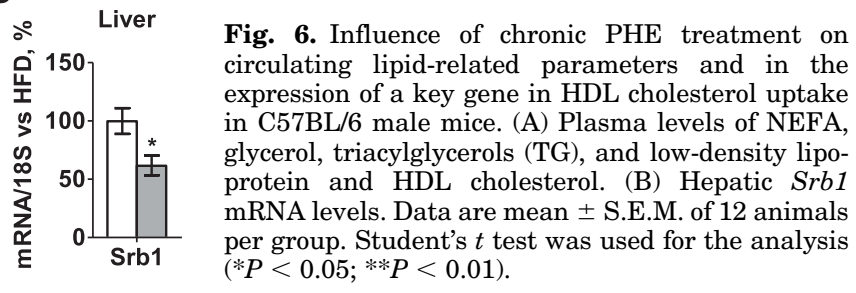

visceral WAT depot weights were unaffected; and 3) $H s l$ was downregulated in iWAT.

SSAO-independent mechanisms could also be involved in the PHE-induced reduction of fat accumulation. Indeed, PHE impairs not only the amine-induced, but also the insulinstimulated de novo lipogenesis in isolated adipocytes (Carpéné et al., 2013, 2014) and in normal-weight mice after chronic treatment (Carpéné et al., 2018c). In the present study, however, the lipogenic action of insulin was not impaired, as was the case for PHE-treated obese Zucker rats and HSD mice (Carpéné et al., 2008, 2018b). This observation suggests that the ability of PHE to inhibit the lipogenic action of insulin could be surpassed in obesity and insulin resistance models. Another target that could mediate the long-term

\section{A}

A $\square$ HFD $\square$ HFD+PHE

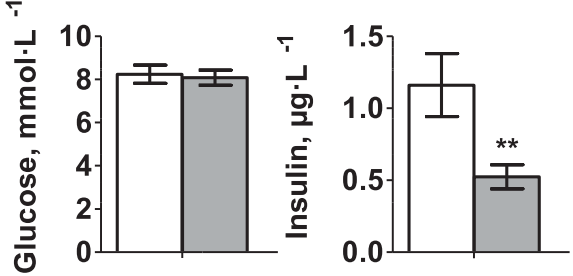

B
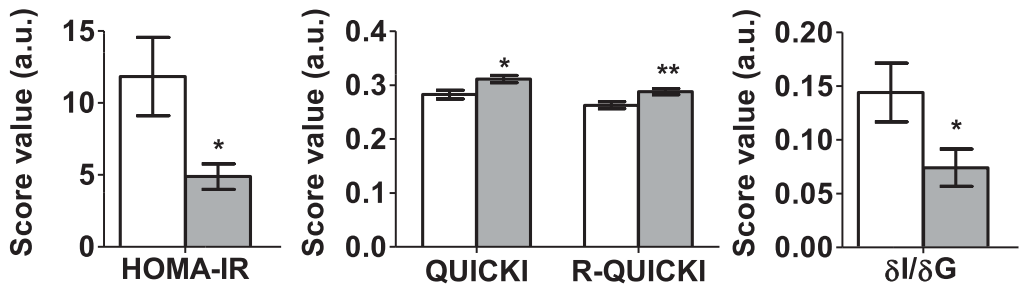

C $\odot$ HFD $\bullet$ HFD+PHE

Fig. 7. Effects of chronic PHE treatment on glucose and insulin homeostasis in C57BL/6 male mice. (A) Overnight fasted blood glucose and insulin levels. (B) Homeostatic model assessment of insulin resistance, QUICKI, revised QUICKI, and $\delta D \mathrm{I} / \delta \mathrm{G}$ scores. (C) Glycaemic response in tolerance test. Data are mean \pm S.E.M. of 12 animals per group. Student's $t$ test was used for the analysis $(* P<0.05$; ${ }^{* *} P<0.01$ ), and two-way repeated measures ANOVA, followed by a Bonferroni post hoc test, was performed to compare the different effects of treatment and time.

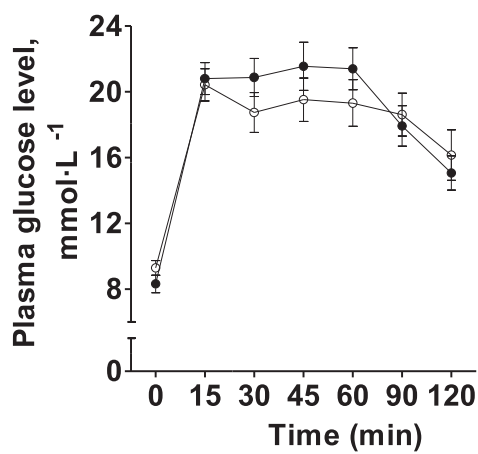


A

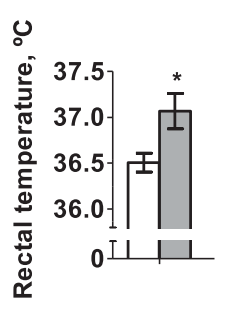

B

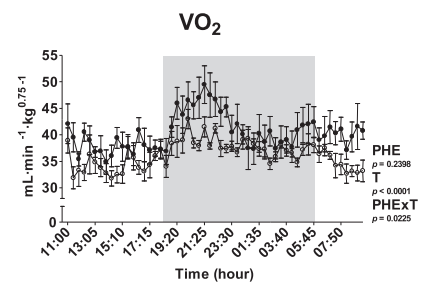

Mean $\mathrm{VCO}_{2}$

C

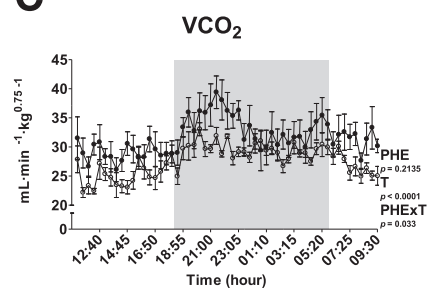

E

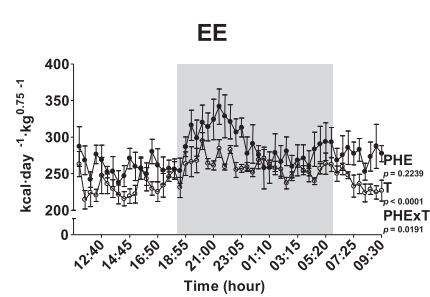

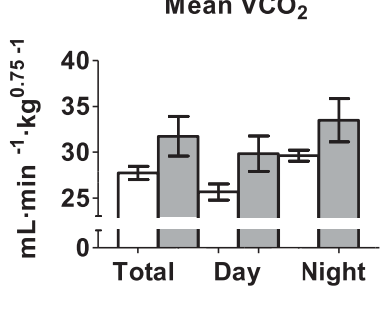

Mean EE

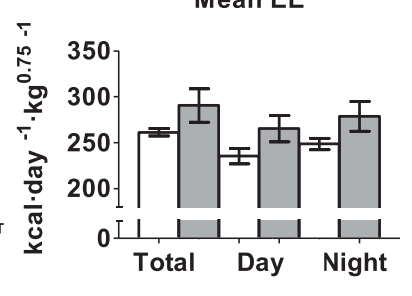

Mean $\mathrm{VO}_{2}$

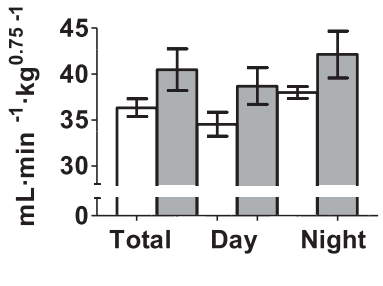

$H F D+P H E$

HFD+PHE
D

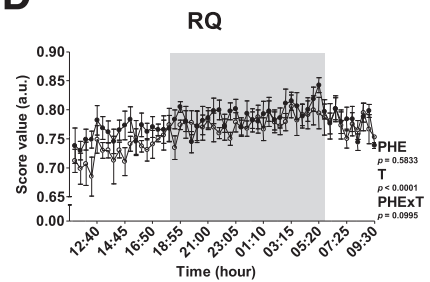

F

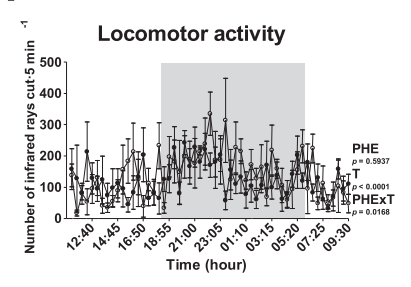

Mean RQ
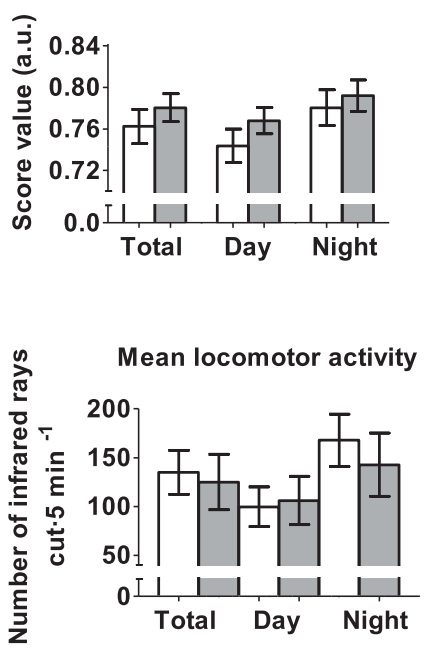

Fig. 8. Effects of chronic PHE treatment on $\mathrm{EE}$ in C57BL/6 male mice. (A) Rectal temperature, $(\mathrm{B}) \mathrm{VO}_{2}\left(\mathrm{O}_{2}\right.$ consumption $),(\mathrm{C}) \mathrm{VCO}_{2}\left(\mathrm{CO} \mathrm{O}_{2}\right.$ production $)$, (D) respiratory quotient $(\mathrm{RQ}),(\mathrm{E}) \mathrm{EE}$, and $(\mathrm{F})$ locomotor activity. Data are mean \pm S.E.M. of six animals per group, except for rectal temperature $(n=12)$. Student's $t$ test and two-way repeated measures ANOVA, followed by a Bonferroni post hoc test, were performed to compare the different effects of treatment and time $(* P<0.05)$. PHE, treatment effect; T, time effect; and PHE $\times$ T, interactive effect between treatment and time.

inhibitory effect of PHE on lipogenesis and adipocyte differentiation is SREBP1c, as shown in cultured differentiating adipocytes (Chiche et al., 2009). In HFD + PHE mice, the expression of Srebp1c and its controlled gene Fas was lower in iWAT and liver and was unchanged in pWAT, where lipid content was unaffected. Furthermore, Srebp1c expression was unchanged in normal-weight and HSD mice after PHE treatments (Carpéné et al., 2018b,c), despite fat pad reduction, suggesting that the drug effect on $S r e b p 1 c$ is dietdependent. Unlike HFD, fructose supplementation strongly induces Srebp1c mRNA expression (Softic et al., 2017). Thus, the inhibitory PHE effect on Srebp1c mRNA could occur particularly under a low-carbohydrate intake, as in HFD, and be masked by the high-fructose intake of mice on a HSD, as well as in standard chow-fed mice having highcarbohydrate intake. Additionally, inhibition of fatty acid re--esterification could be involved in the reduced fat accumulation in liver and iWAT because both hepatocytes and adipocytes synthesize triacylglycerols using PEPCK-produced glycerol-3-phosphate (Prentki and Madiraju, 2008). This is suggested by the lower circulating glycerol and hepatic and adipose Pepck expression in HFD + PHE mice. Moreover, epigenetic mechanisms might be involved in the depot-specific PHE effects on adipose cells because the drug affects the differentiation of stem cells by modulating histone methylation status (Yan et al., 2016).

Our results suggest a reduction of hepatic steatosis and inflammation, which could contribute to the amelioration of liver function, as shown by the normalization of transaminase levels. The lower hepatic lipid content together with the reduced triglyceridemia in HFD + PHE mice suggests that the hepatic triacylglycerol synthesis capacity could be impaired, which is supported by the reduced Srebp1c, Fas, and Pepck expression. Furthermore, the reduction of the HFD-induced proinflammatory state is supported by the reduced expression of IL- 6 and tumor necrosis factor- $\alpha$ cytokines, which were also inhibited by PHE in other models of inflammation (Ekuni et al., 2009; Li et al., 2018). Remarkably, the PHE effect on these cytokines also occurs in the adipose tissue, more conspicuously in the visceral pad in which the inflammatory status is higher than in the subcutaneous pad. In addition, the inhibition of the enzymatic SSAO/VAP-1 activity, observed in both liver and adipose tissue of HFD + PHE mice, could mediate the reduced hepatic and adipose inflammation because the catalytic activity is required in its role in leukocyte transmigration and inflammation (Koskinen et al., 2004; Weston et al., 2015). The combined downregulation of proinflammatory cytokines and of leukocyte infiltration markers, seen in liver, pWAT, and iWAT, supports the inhibitory role of the hydrazine on the low-grade inflammation associated with obesity.

Interestingly, the reduction of fat accumulation and body weight was not accompanied by changes in food consumption, in accordance with the previous results obtained in mice with different dietary conditions (Carpéné et al., 2018b,c) or 
TABLE 2

Influence of PHE chronic treatment on the expression of genes related to oxidative metabolism in mice fed a HFD

Eleven-week-old C57BL/6 male mice on a HFD received water or $88.9 \mu \mathrm{mol} \mathrm{PHE} / \mathrm{kg}$ body weight per day to drink (HFD + PHE) for 11 wk. Gene expression of $\mathrm{Cpt1b}$ (carnitine palmitoyltransferase 1B), Ppara (peroxisome proliferator-activated receptor $\alpha$ ), Ppargc1a (peroxisome proliferator-activated receptor $\gamma$ coactivator 1- $\alpha$ ), Foxc2 (forkhead box C2), Vegf (vascular endothelial growth factor), Ucp1 (uncoupling protein 1), Acc2 (acetyl carboxylase 2), Cd36 (cluster of differentiation 36), and Glut4 (glucose transporter 4). Data are the mean \pm S.E.M. of $n=12$ /group. A Student's $t$ test was performed. Difference HFD vs. HFD + PHE mice: $* P<0.05 ; * * P<0.01$; $t$ test was perfort
$* * * P<0.001$.

\begin{tabular}{llcl}
\hline Parameter & HFD & HFD + PHE & P Value \\
\hline iBAT & $100 \pm 9$ & $123 \pm 8^{*}$ & \\
Cpt1b & $100 \pm 11$ & $123 \pm 14$ & \\
Ppara & $100 \pm 22$ & $136 \pm 27$ & \\
Ppargc1a & $100 \pm 14$ & $111 \pm 15$ & \\
Foxc2 & $100 \pm 9$ & $125 \pm 10$ & 0.061 \\
Vegf & $100 \pm 11$ & $119 \pm 10$ & \\
Ucp1 & & & \\
Liver & $100 \pm 14$ & $53 \pm 9^{* *}$ & \\
Acc2 & $100 \pm 9$ & $48 \pm 5^{* * *}$ & \\
Ppara & & & \\
Skeletal muscle & $100 \pm 25$ & $71 \pm 7$ & 0.056 \\
Cd36 & $100 \pm 8$ & $81 \pm 3$ & \\
Glut4 & $100 \pm 7$ & $109 \pm 15$ & \\
Ucp3 & $100 \pm 8$ & $84 \pm 8$ & \\
Ppargc1a & $100 \pm 12$ & $69 \pm 4^{* *}$ & \\
Ppara & $100 \pm 7$ & $75 \pm 5^{* *}$ & \\
Cpt1b & & & \\
\hline
\end{tabular}

PHE-injected rats (Carpéné et al., 2008). This observation contrasts with the higher food intake and craving reported in PHE-treated patients and with the inhibitory effect on food consumption induced by semicarbazide that contributes to reduced body weight (Carpéné et al., 2007, 2008; Mercader et al., 2011) and seems to indicate that neuronal transmission is exquisitely regulated by monaminergic systems that are differentially regulated upon MAO inhibition.

The hypoglycemic effect of PHE reported in patients with depression and mood disorders (McIntyre et al., 2006) has been explained by hepatic gluconeogenesis inhibition, intestinal glucose uptake impairment, and/or enhanced insulin release (Aleyassine and Gardiner, 1975; Feldman and Chapman, 1975; Haeckel and Oellerich, 1977; Haeckel et al., 1984). According to an in vitro study with high PHE doses, the effect on insulin release is, however, the opposite (Aleyassine and Gardiner, 1975). Therefore, it is relevant to investigate whether PHE can reduce hyperglycemia and hyperinsulinemia in animal models of obesity and insulin resistance. Interestingly, in HSD mice, which did not develop insulin resistance, PHE restored high-glucose levels (Carpéné et al., $2018 \mathrm{~b})$. However, considering that the insulin-like effect of AO substrates on glucose transport in adipocytes depends on their oxidation (Visentin et al., 2005; Mercader et al., 2010), it remains difficult to understand how AO inhibitors can reduce hyperglycemia or improve glucose tolerance. In this study, in insulin-resistant mice, PHE did not affect hyperglycemia and glucose tolerance. However, HFD + PHE mice consistently attenuated hyperinsulinemia and insulin resistance. Because both fasting and feeding glycaemia were not changed by PHE treatment, it is unlikely that a strong inhibition of hepatic gluconeogenesis and intestinal glucose uptake occurred in HFD + PHE mice. A direct effect on insulin release through a MAO-independent mechanism cannot be excluded (Feldman and Chapman, 1975), despite the fact that the dose at which PHE could inhibit insulin release
(Aleyassine and Gardiner, 1975) is not expected to be reached in HFD + PHE mice. In addition, the amelioration of insulin sensitivity could be an indirect consequence of the treatment as a result of the reduced adiposity, proinflammatory cytokine, and/or $\mathrm{H}_{2} \mathrm{O}_{2}$ production.

The lack of reduction of malondialdehyde is apparently disappointing because PHE is endowed with scavenging properties toward aldehydes and oxidative stress (Galvani et al., 2008; Baker et al., 2019). Two hypotheses can explain this: 1) the protective effect of PHE was probably insufficient to limit the dramatic increase of systemic markers of oxidative stress developed by HFD (Sonta et al., 2004), and 2) the changes in malondialdehyde plasma levels did not reflect the complex and depot-specific changes in lipid peroxidation products occurring in adipose tissue (Long et al., 2013).

Rectal temperature, an indicator of EE, was increased by PHE, as in HSD mice (Carpéné et al., 2018b). Such thermogenic effect of PHE might be caused by increased 5-HT levels, which together with noradrenaline control body temperature (Bruinvels and Kemper, 1971). The potential PHE-induced BAT activation seems to not occur in HFD mice, but it cannot be ruled out because an increased $C p t 1$ mRNA expression suggests a higher fatty acid $\beta$-oxidation rate. Regardless of the lack of dramatic BAT recruitment, we further evaluated the potential changes in EE, which could have been produced by the elevation in catecholamine and trace amine levels after AO inhibition (Baker et al., 2000). Accordingly, a local increase in catecholamine levels induced by the administration of reuptake inhibitors caused weight loss by increasing locomotor activity and thermogenesis (Billes and Cowley, 2008). PHE could increase EE by enhancing the spontaneous locomotor activity because it decreases immobility time in the forced-swim test (Zhao et al., 2009) and attenuates motor-suppressant effects (McManus and Greenshaw, 1991). The increased activity is thought to be mediated by reducing either $\alpha$ - or $\beta_{2}$ adrenoreceptor sensitivity (McManus and Greenshaw, 1991; McKenna et al., 1992; Paetsch and Greenshaw, 1993). The latter is attributed to an increase in 2-phenylethylamine (McManus and Greenshaw, 1991), a PHE metabolite (Baker et al., 2000), which reduces, as $\mathrm{PHE}$, the behavioral response to a $\beta_{2^{-}}$ adrenoceptor agonist (Paetsch and Greenshaw, 1993) and is associated with a decrease in body weight (Pawar and Grundel, 2017). However, lack of changes in the locomotor activity suggests that it does not contribute to the attenuation of metabolic disturbances exhibited by PHE-drinking mice, further supported by the lack of increase in the expression of genes involved in fuel utilization in the skeletal muscle. Oxygen consumption, RQ, and EE tended to be higher in HFD + PHE mice. Unfortunately, these parameters were obtained from six animals per group only, therefore reducing statistical power.

The exciting findings reported in this study indicate that PHE mitigates several metabolic alterations developed by a HFD. Further studies are warranted to perhaps consider PHE as useful for a multitherapy treatment of obesity and its cardiovascular and neurologic complications.

\section{Acknowledgments}

We are grateful to Estelle Wanecq (I2MC, Toulouse) for help in extraction and to Antonio Zorzano (IRB, Barcelona) for facilitating collaborations beyond DIOmed project. 


\section{Authorship Contributions}

Participated in research design: Mercader, Carpéné.

Conducted experiments: Mercader, Le Gonidec, Decaunes, Gómez-

Zorita, Carpéné.

Performed data analysis: Mercader, Sabater, Le Gonidec, Carpéné.

Wrote or contribute to the writing of the manuscript: Mercader, Chaplin, Milagro, Carpéné.

\section{References}

Aleyassine H and Gardiner RJ (1975) Dual action of antidepressant drugs (MAO inhibitors) on insulin release. Endocrinology 96:702-710.

Baker G, Matveychuk D, MacKenzie EM, Holt A, Wang Y, and Kar S (2019) Attenuation of the effects of oxidative stress by the MAO-inhibiting antidepressant and carbonyl scavenger phenelzine. Chem Biol Interact 304:139-147.

Baker GB, Coutts RT, and Greenshaw AJ (2000) Neurochemical and metabolic aspects of antidepressants: an overview. J Psychiatry Neurosci 25:481-496.

Bashan N, Kovsan J, Kachko I, Ovadia H, and Rudich A (2009) Positive and negative regulation of insulin signaling by reactive oxygen and nitrogen species. Physiol Rev 89:27-71.

Billes SK and Cowley MA (2008) Catecholamine reuptake inhibition causes weight loss by increasing locomotor activity and thermogenesis. Neuropsychopharmacology 33:1287-1297.

Bour S, Caspar-Bauguil S, Iffiú-Soltész Z, Nibbelink M, Cousin B, Miiluniemi M, Salmi M, Stolen C, Jalkanen S, Casteilla L, et al. (2009) Semicarbazide-sensitive amine oxidase/vascular adhesion protein-1 deficiency reduces leukocyte infiltration into adipose tissue and favors fat deposition. Am J Pathol 174:1075-1083.

Bruinvels J and Kemper GC (1971) Role of noradrenaline and 5-hydroxytryptamine in tetrahydronaphthylamine-induced temperature changes in the rat. $\mathrm{Br}$ J Pharmacol 43:1-9.

Carpéné C, Abello V, Iffiú-Soltész Z, Mercier N, Fève B, and Valet P (2008) Limitation of adipose tissue enlargement in rats chronically treated with semicarbazide-sensitive amine oxidase and monoamine oxidase inhibitors. Pharmacol Res 57:426-434.

Carpéné C, Boulet N, Chaplin A, and Mercader J (2019) Past, present and future anti-obesity effects of flavin-containing and/or copper-containing amine oxidase inhibitors. Medicines (Basel) 6:E9.

Carpéné C, Galitzky J, Belles C, and Zakaroff-Girard A (2018a) Mechanisms of the antilipolytic response of human adipocytes to tyramine, a trace amine present in food. J Physiol Biochem 74:623-633.

Carpéné C, Gómez-Zorita S, Chaplin A, and Mercader J (2018b) Metabolic effects of oral phenelzine treatment on high-sucrose-drinking mice. Int J Mol Sci 19:E2904.

Carpéné C, Gomez-Zorita S, Gupta R, Grès S, Rancoule C, Cadoudal T, Mercader J, Gomez A, Bertrand C, and Iffiu-Soltész Z (2014) Combination of low dose of the anti-adipogenic agents resveratrol and phenelzine in drinking water is not sufficient to prevent obesity in very-high-fat diet-fed mice. Eur $J$ Nutr 53: 1625-1635.

Carpéné C, Grès S, and Rascalou S (2013) The amine oxidase inhibitor phenelzine limits lipogenesis in adipocytes without inhibiting insulin action on glucose uptake. $J$ Neural Transm (Vienna) 120:997-1003.

Carpéné C, Iffiú-Soltesz Z, Bour S, Prévot D, and Valet P (2007) Reduction of fat deposition by combined inhibition of monoamine oxidases and semicarbazidesensitive amine oxidases in obese Zucker rats. Pharmacol Res 56:522-530.

Carpéné C, Les F, Hasnaoui M, Biron S, Marceau P, Richard D, Galitzky J, Joanisse $\mathrm{DR}$, and Mauriège $\mathrm{P}$ (2016) Anatomical distribution of primary amine oxidase activity in four adipose depots and plasma of severely obese women with or without a dysmetabolic profile. J Physiol Biochem 73:475-486

Carpéné C, Mercader J, Le Gonidec S, Schaak S, Mialet-Perez J, Zakaroff-Girard A and Galitzky J (2018c) Body fat reduction without cardiovascular changes in mice after oral treatment with the MAO inhibitor phenelzine. $\mathrm{Br} J$ Pharmacol 175 2428-2440.

Chiche F, Le Guillou M, Chétrite G, Lasnier F, Dugail I, Carpéné C, Moldes M, and Fève B (2009) Antidepressant phenelzine alters differentiation of cultured human and mouse preadipocytes. Mol Pharmacol 75:1052-1061.

Curtis MJ, Alexander S, Cirino G, Docherty JR, George CH, Giembycz MA, Hoyer D, Insel PA, Izzo AA, Ji Y, et al. (2018) Experimental design and analysis and their reporting II: updated and simplified guidance for authors and peer reviewers. $\mathrm{Br}$ $J$ Pharmacol 175:987-993.

Dole VP and Meinertz H (1960) Microdetermination of long-chain fatty acids in plasma and tissues. J Biol Chem 235:2595-2599.

Ekuni D, Firth JD, Nayer T, Tomofuji T, Sanbe T, Irie K, Yamamoto T, Oka T, Liu Z, Vielkind J, et al. (2009) Lipopolysaccharide-induced epithelial monoamine oxidase mediates alveolar bone loss in a rat chronic wound model. Am J Pathol 175: 1398-1409.

Feldman JM and Chapman B (1975) Monoamine oxidase inhibitors: nature of their interaction with rabbit pancreatic islets to alter insluin secretion. Diabetologia 11 487-494

Galvani S, Coatrieux C, Elbaz M, Grazide MH, Thiers JC, Parini A, Uchida K, Kamar N, Rostaing L, Baltas M, et al. (2008) Carbonyl scavenger and antiatherogenic effects of hydrazine derivatives. Free Radic Biol Med 45:1457-1467.

Haeckel R and Oellerich M (1977) The influence of hydrazine, phenelzine and nialamide on gluconeogenesis and cell respiration in the perfused Guinea-pig liver. Eur $J$ Clin Invest 7:393-400.

Haeckel R, Terlutter H, Schumann G, and Oellerich M (1984) Hydrazonopropionic acids, a new class of hypoglycemic substances, 3 . Inhibition of jejunal glucose uptake in the rat and guinea pig. Horm Metab Res 16:423-427.

Harant-Farrugia I, Garcia J, Iglesias-Osma MC, Garcia-Barrado MJ, and Carpéné C (2014) Is there an optimal dose for dietary linoleic acid? Lessons from essential fatty acid deficiency supplementation and adipocyte functions in rats. $J$ Physiol Biochem 70:615-627.

Iglesias-Osma MC, Garcia-Barrado MJ, Visentin V, Pastor-Mansilla MF, Bour S, Prévot D, Valet P, Moratinos J, and Carpéné C (2004) Benzylamine exhibits insulin-like effects on glucose disposal, glucose transport, and fat cell lipolysis in rabbits and diabetic mice. J Pharmacol Exp Ther 309:1020-1028.

Jalkanen S and Salmi M (1993) A novel endothelial cell molecule mediating lymphocyte binding in humans. Behring Inst Mitt 92:36-43.

Katz A, Nambi SS, Mather K, Baron AD, Follmann DA, Sullivan G, and Quon MJ (2000) Quantitative insulin sensitivity check index: a simple, accurate method for assessing insulin sensitivity in humans. J Clin Endocrinol Metab 85:2402-2410.

Kilkenny C, Browne W, Cuthill IC, Emerson M, and Altman DG; NC3Rs Reporting Guidelines Working Group (2010) Animal research: reporting in vivo experiments: the ARRIVE guidelines. Br J Pharmacol 160:1577-1579.

Koskinen K, Vainio PJ, Smith DJ, Pihlavisto M, Ylä-Herttuala S, Jalkanen S, and Salmi M (2004) Granulocyte transmigration through the endothelium is regulated by the oxidase activity of vascular adhesion protein-1 (VAP-1). Blood 103: $3388-3395$

Li R, Sahu S, and Schachner M (2018) Phenelzine, a small organic compound mimicking the functions of cell adhesion molecule L1, promotes functional recovery after mouse spinal cord injury. Restor Neurol Neurosci 36:469-483.

Long EK, Olson DM, and Bernlohr DA (2013) High-fat diet induces changes in adipose tissue trans-4-oxo-2-nonenal and trans-4-hydroxy-2-nonenal levels in a depotspecific manner. Free Radic Biol Med 63:390-398.

Matthews DR, Hosker JP, Rudenski AS, Naylor BA, Treacher DF, and Turner RC (1985) Homeostasis model assessment: insulin resistance and beta-cell function from fasting plasma glucose and insulin concentrations in man. Diabetologia 28 : $412-419$.

McGrath JC and Lilley E (2015) Implementing guidelines on reporting research using animals (ARRIVE etc.): new requirements for publication in BJP. $B r$ $J$ Pharmacol 172:3189-3193.

McIntyre RS, Soczynska JK, Konarski JZ, and Kennedy SH (2006) The effect of antidepressants on glucose homeostasis and insulin sensitivity: synthesis and mechanisms. Expert Opin Drug Saf 5:157-168.

McKenna KF, Baker GB, Coutts RT, and Greenshaw AJ (1992) Chronic administration of the antidepressant-antipanic drug phenelzine and its $\mathrm{N}$-acetylated analogue: effects on monoamine oxidase, biogenic amines, and alpha 2 adrenoreceptor function. J Pharm Sci 81:832-835.

McManus DJ and Greenshaw AJ (1991) Differential effects of chronic antidepressants in behavioural tests of beta-adrenergic and GABAB receptor function. Psychopharmacology (Berl) 103:204-208.

Mercader J, Iffiú-Soltész Z, Bour S, and Carpéné C (2011) Oral administration of semicarbazide limits weight gain together with inhibition of fat deposition and of primary amine oxidase activity in adipose tissue. $J$ Obes 2011:475786.

Mercader J, Iffiú-Soltesz Z, Brenachot X, Földi A, Dunkel P, Balogh B, Attané C, Valet P, Mátyus P, and Carpéné C (2010) SSAO substrates exhibiting insulin-like effects in adipocytes as a promising treatment option for metabolic disorders. $\mathrm{Fu}$ ture Med Chem 2:1735-1749.

Minet-Ringuet J, Even PC, Valet P, Carpéné C, Visentin V, Prévot D, Daviaud D, Quignard-Boulange A, Tomé D, and de Beaurepaire R (2007) Alterations of lipid metabolism and gene expression in rat adipocytes during chronic olanzapine treatment. Mol Psychiatry 12:562-571.

Morin N, Lizcano JM, Fontana E, Marti L, Smih F, Rouet P, Prévot D, Zorzano A Unzeta M, and Carpéné C (2001) Semicarbazide-sensitive amine oxidase substrates stimulate glucose transport and inhibit lipolysis in human adipocytes. $J$ Pharmacol Exp Ther 297:563-572.

Mustafa AG, Alfaqih MA, and Al-Shboul O (2018a) The 4-hydroxynonenal mediated oxidative damage of blood proteins and lipids involves secondary lipid peroxidation reactions. Exp Ther Med 16:2132-2137.

Mustafa AG, Al-Shboul O, Alfaqih MA, Al-Qudah MA, and Al-Dwairi AN (2018b) Phenelzine reduces the oxidative damage induced by peroxynitrite in plasma lipids and proteins. Arch Physiol Biochem 124:418-423.

O'Rourke AM, Wang EY, Miller A, Podar EM, Scheyhing K, Huang L, Kessler C, Gao H, Ton-Nu HT, Macdonald MT, et al. (2008) Anti-inflammatory effects of LJP 1586 [Z-3-fluoro-2-(4-methoxybenzyl)allylamine hydrochloride], an amine-based inhibitor of semicarbazide-sensitive amine oxidase activity. J Pharmacol Exp Ther $\mathbf{3 2 4}$ $867-875$

Paetsch PR and Greenshaw AJ (1993) 2-Phenylethylamine-induced changes in catecholamine receptor density: implications for antidepressant drug action. Neurochem Res 18:1015-1022.

Pannecoeck R, Serruys D, Benmeridja L, Delanghe JR, van Geel N, Speeckaert R, and Speeckaert MM (2015) Vascular adhesion protein-1: role in human pathology and application as a biomarker. Crit Rev Clin Lab Sci 52:284-300.

Pawar RS and Grundel E (2017) Overview of regulation of dietary supplements in the USA and issues of adulteration with phenethylamines (PEAs). Drug Test Anal 9: 500-517.

Perseghin G, Caumo A, Caloni M, Testolin G, and Luzi L (2001) Incorporation of the fasting plasma FFA concentration into QUICKI improves its association with insulin sensitivity in nonobese individuals. J Clin Endocrinol Metab 86:4776-4781.

Prentki M and Madiraju SR (2008) Glycerolipid metabolism and signaling in health and disease. Endocr Rev 29:647-676.

Prévot D, Soltesz Z, Abello V, Wanecq E, Valet P, Unzeta M, and Carpéné C (2007) Prolonged treatment with aminoguanidine strongly inhibits adipocyte semicarbazidesensitive amine oxidase and slightly reduces fat deposition in obese Zucker rats. Pharmacol Res 56:70-79.

Salter-Cid LM, Wang E, O'Rourke AM, Miller A, Gao H, Huang L, Garcia A and Linnik MD (2005) Anti-inflammatory effects of inhibiting the amine oxidase activity of semicarbazide-sensitive amine oxidase. $J$ Pharmacol Exp Ther $\mathbf{3 1 5}$ $553-562$

Softic S, Gupta MK, Wang GX, Fujisaka S, O’Neill BT, Rao TN, Willoughby J, Harbison C, Fitzgerald K, Ilkayeva O, et al. (2017) Divergent effects of glucose 
and fructose on hepatic lipogenesis and insulin signaling. $J$ Clin Invest 127: 4059-4074.

Song MS, Matveychuk D, MacKenzie EM, Duchcherer M, Mousseau DD, and Baker GB (2013) An update on amine oxidase inhibitors: multifaceted drugs. Prog Neuropsychopharmacol Biol Psychiatry 44:118-124.

Sonta T, Inoguchi T, Tsubouchi H, Sekiguchi N, Kobayashi K, Matsumoto S, Utsum $\mathrm{H}$, and Nawata $\mathrm{H}(2004)$ Evidence for contribution of vascular NAD(P)H oxidase to increased oxidative stress in animal models of diabetes and obesity. Free Radic Biol Med 37:115-123.

Vachharajani V and Granger DN (2009) Adipose tissue: a motor for the inflammation associated with obesity. IUBMB Life 61:424-430.

Visentin V, Bour S, Boucher J, Prévot D, Valet P, Ordener C, Parini A, and Carpéné C (2005) Glucose handling in streptozotocin-induced diabetic rats is improved by tyramine but not by the amine oxidase inhibitor semicarbazide. Eur J Pharmacol 522:139-146.

Wang EY, Gao H, Salter-Cid L, Zhang J, Huang L, Podar EM, Miller A, Zhao J, O'rourke A, and Linnik MD (2006) Design, synthesis, and biological evaluation of semicarbazide-sensitive amine oxidase (SSAO) inhibitors with anti-inflammatory activity. J Med Chem 49:2166-2173.

Wang SH, Yu TY, Tsai FC, Weston CJ, Lin MS, Hung CS, Kao HL, Li YI, Solé M, Unzeta M, et al. (2018) Inhibition of semicarbazide-sensitive amine oxidase reduces atherosclerosis in apolipoprotein E-deficient mice. Transl Res 197:12-31.

Weston CJ, Shepherd EL, Claridge LC, Rantakari P, Curbishley SM, Tomlinson JW, Hubscher SG, Reynolds GM, Aalto K, Anstee QM, et al. (2015) Vascular adhesion protein-1 promotes liver inflammation and drives hepatic fibrosis. $J$ Clin Invest 125:501-520.
Yan HJ, Zhou SY, Li Y, Zhang H, Deng CY, Qi H, and Li FR (2016) The effects of LSD1 inhibition on self-renewal and differentiation of human induced pluripotent stem cells. Exp Cell Res 340:227-237.

Zhao Z, Zhang HT, Bootzin E, Millan MJ, and O’Donnell JM (2009) Association of changes in norepinephrine and serotonin transporter expression with the longterm behavioral effects of antidepressant drugs. Neuropsychopharmacology 34: 1467-1481.

Zhou M and Panchuk-Voloshina N (1997) A one-step fluorometric method for the continuous measurement of monoamine oxidase activity. Anal Biochem 253: 169-174.

Zimmermann U, Kraus T, Himmerich H, Schuld A, and Pollmächer T (2003) Epidemiology, implications and mechanisms underlying drug-induced weight gain in psychiatric patients. J Psychiatr Res 37:193-220.

Zorzano A, Abella A, Marti L, Carpéné C, Palacín M, and Testar X (2003) Semicarbazide-sensitive amine oxidase activity exerts insulin-like effects on glucose metabolism and insulin-signaling pathways in adipose cells. Biochim Biophys Acta 1647:3-9.

Address correspondence to: Dr. Josep Mercader, Crta Valldemossa km 7,5, Edifici Mateu Orfila, Universitat de les Illes Balears, Palma, 07122, Spain. E-mail: josep.mercader@uib.es; or Dr. Christian Carpéné, Institute of Metabolic and Cardiovascular Diseases, INSERM, UMR1048, 31432 Toulouse, France. E-mail: christian.carpene@inserm.fr 